\title{
Why Fast Trains Work: An Assessment of a Fast Regional Rail System in Perth, Australia
}

\author{
James McIntosh $^{1}$, Peter Newman ${ }^{1}$, Garry Glazebrook ${ }^{2}$ \\ ${ }^{1}$ Curtin University Sustainability Policy (CUSP) Institute, Fremantle, Australia \\ ${ }^{2}$ University of Technology, Sydney (UTS), Sydney, Australia \\ Email: james.r.mcintosh@postgrad.curtin.edu.au, P.Newman@curtin.edu.au, Garry.Glazebrook@uts.edu.au
}

Received January 29, 2013; revised March 2, 2013; accepted March 9, 2013

Copyright (c) 2013 James McIntosh et al. This is an open access article distributed under the Creative Commons Attribution License, which permits unrestricted use, distribution, and reproduction in any medium, provided the original work is properly cited.

\begin{abstract}
Perth's new $72 \mathrm{~km}$ long Southern Rail System opened in 2007. With a maximum speed of $137 \mathrm{~km} / \mathrm{hr}$ and an average speed of almost $90 \mathrm{~km} / \mathrm{hr}$ this system acts more like a new high speed rail than a suburban rail system, which in Australia typically averages around $40 \mathrm{~km} / \mathrm{hr}$ for an all-stops services. The Southern Rail Line was very controversial when being planned as the urban areas served are not at all typical of those normally provided with rail but instead were highly car dependent and scattered low density land uses. Nevertheless it has been remarkably successful, carrying over 70,000 people per day (five times the patronage on the express buses it replaced) and has reached the patronage levels predicted for 2021 a decade ahead of time. The reasons for this success are analyzed and include well-designed interchanges, careful integration of bus services, the use of integrated ticketing and fares without transfer penalties and, crucially the high speed of the system when compared to competing car based trips. The Southern Rail Line in effect explodes the current paradigm of transfer penalties, exposing this as a myth. The lessons for transport planning in low density cities are significant, and are explored further in the paper.
\end{abstract}

Keywords: Integrated Ticketing; Fast Rail; Multimodal Patronage Modelling; Feeder Buses; Perth; Western Australia

\section{Introduction}

This paper will try to suggest why a fast rail line that runs within the urban region of Perth works so well and why this may help in the assessment of high speed rail projects. We will initially provide a background to the Southern Rail infrastructure and the catchment which it serves, followed by a description of the Southern Rail patronage model, the rail line's operational model, and a description of its station configurations. This background information will lead to a more detailed discussion of the time and financial costs, or "generalized cost" comparesons between private vehicles and public transport within the Southern Rail's catchment.

Through this lens the paper demonstrates that the Southern Rail line's success in generating a significant mode shift to public transport has occurred through physical, operational and regulatory integration. The paper concludes by examining the possible implications of high speed integrated urban rail systems for making travel in dispersed cities more sustainable.

\section{Background to the Perth Southern Rail}

The Perth Southern Suburbs rail line opened on the 23rd of December 2007, and it runs $72 \mathrm{~km}$ from the Perth CBD to Western Australia's second largest city at Mandurah at speeds up to $137 \mathrm{~km} / \mathrm{hr}$. The rail line runs for 70 $\mathrm{km}$ of its $72 \mathrm{~km}$ length at grade in the median and along the western edge of the Kwinana Freeway.

The line has eleven rail stations along the way at major centers and major road intersections including the underground Perth CBD and Esplanade Stations (see Figure 1), with 18 new bridges and 5500 park and ride bays [1].

The Perth Southern Suburbs rail line replaced an existing separated Rapid Busway-based service with an integrated multimodal bus-rail service. The introduction of the rail service cut the journey time from approximately 68 minutes to 48 minutes for the journey from Mandurah to Perth, and increased the existing busway's patronage from approximately 14,000 boarding's/day [2] to the rail line's 48,000 when opened in early 2008 and to 70,000 boarding's/day in 2013.

The Perth Southern Rail Line catchment density (presented in Figure 2) is mainly between 6 - 15 dwellings per hectare, which is a very low dwelling density for rail-based public transport services to be considered viable. South of Murdoch station, the average density of 


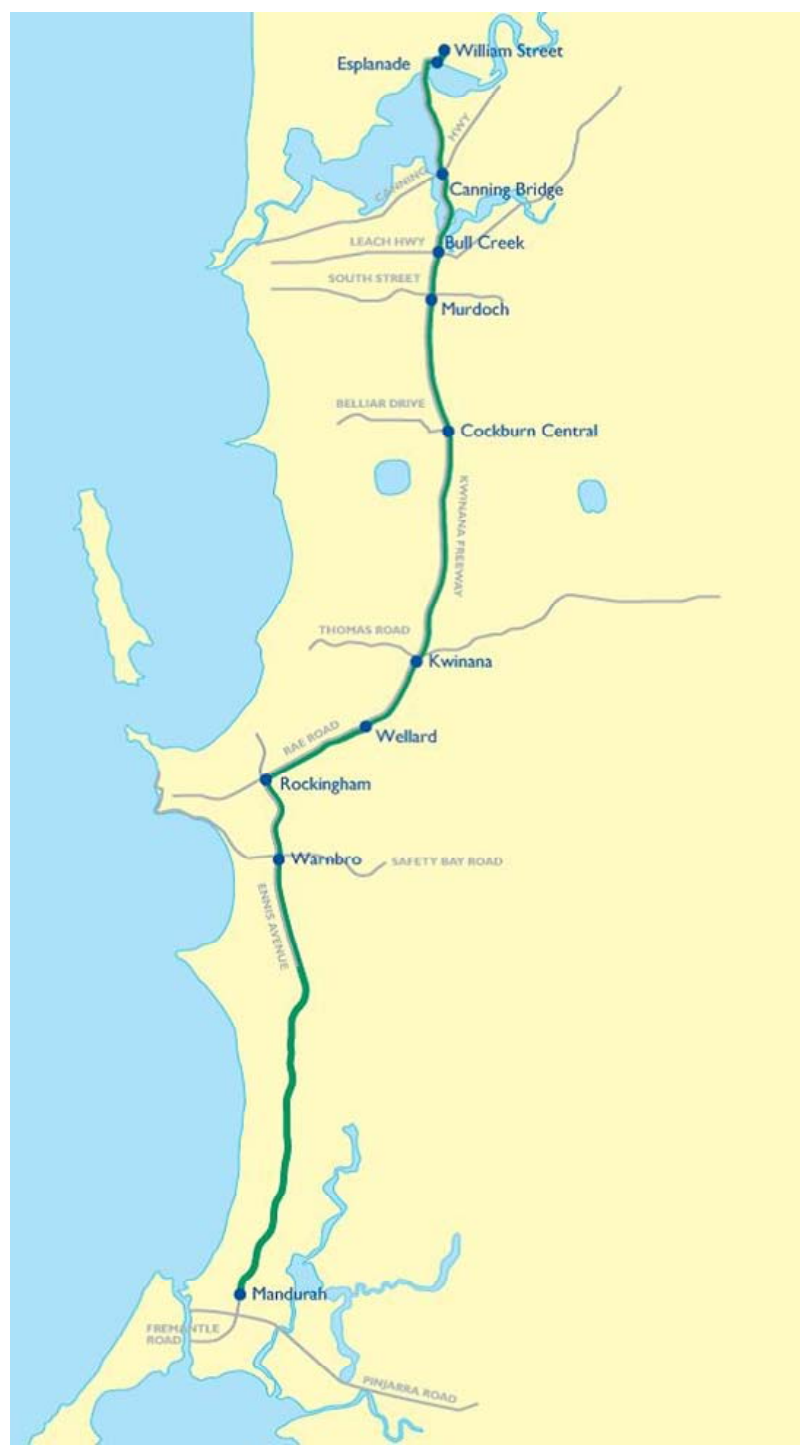

Figure 1. The Perth Southern Rail Line stops and key feeder roads/bus routes [1].

development is even lower, with significant gaps of rural land between settlements.

\section{Perth Southern Rail Patronage Model}

The Perth Southern Rail Line was the second in Australia to be implemented in the median of an existing freeway (after the section to the north of Perth). As a result, there is only limited pedestrian catchment along the alignment. The business case patronage model for the Perth Southern rail line assumed [1]:

- $9 \%$ pedestrian (walk-able) catchment.

91\% patronage to come from outside the pedestrian catchment, comprising.

- $28 \%$ of total patronage to come from the 5260 park and ride bays.

$63 \%$ of the total patronage to come from kiss and ride

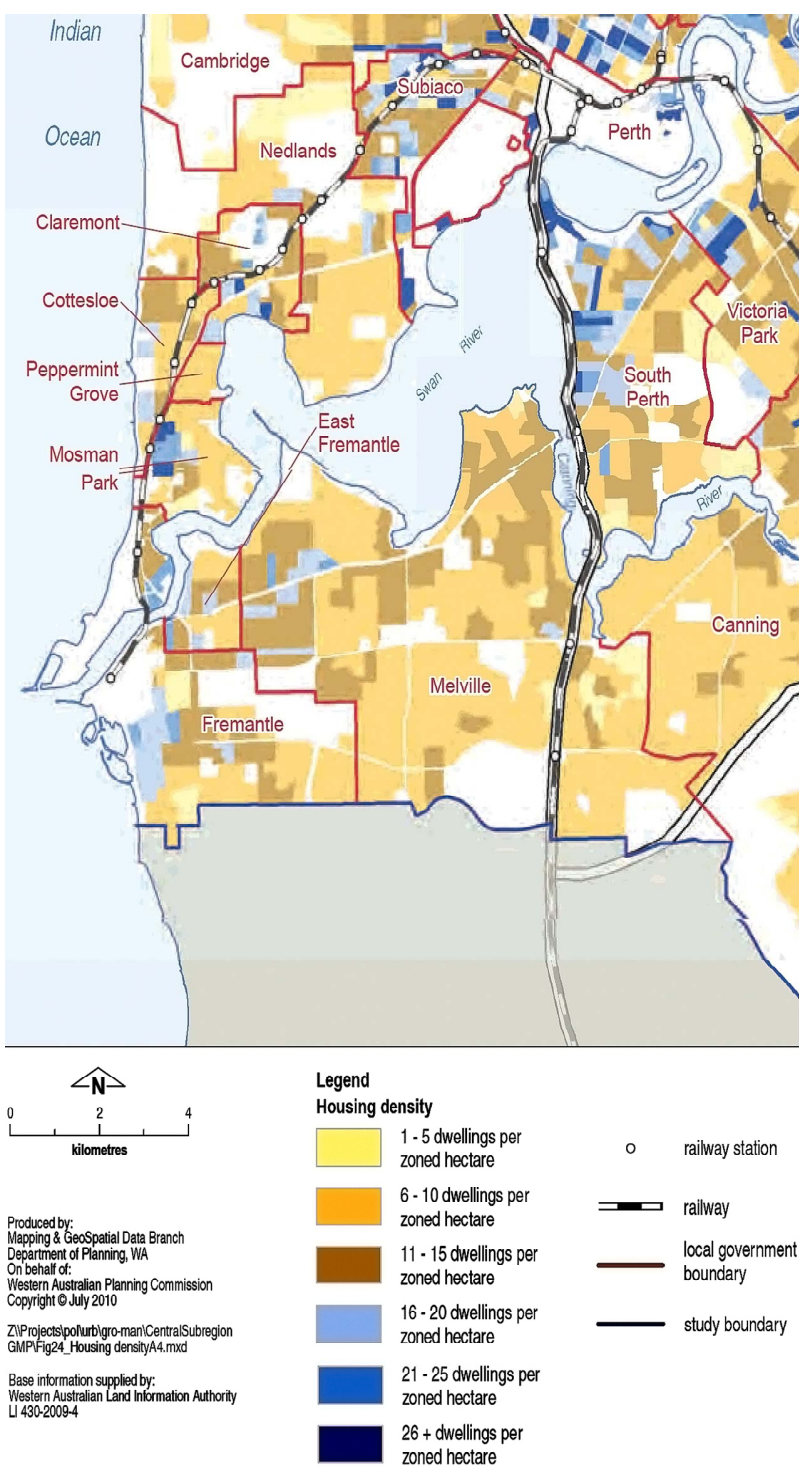

Figure 2. The Perth Southern Rail Line station catchment densities [3].

and the feeder bus services.

The low pedestrian catchment model for public transport infrastructure is a major shift for the roles of the different public transport modes, with the park and ride facilities and closely integrated bus interchanges designed to extend the rail line's catchments into the low density surrounding suburbs, using the regional bus network as a feeder service for areas that had previously been car dependent.

As discussed later, actual patronage has been significantly higher than forecast, particularly from the feeder bus system. As a result, $85 \%$ of the Southern Rail patrons access the train by a bus service, (or line to line transfer), around $8 \%$ from the park and ride and the remainder from pedestrian catchment and kiss and ride [4]. This patronage model appears to be a major part of the suc- 
cess of the rail system.

The other major difference to other public transport systems in Australia is that the public transport system was designed to be competitive with the private motor vehicle in both time and cost (Generalized cost). This low generalized cost model is a function of the station configurations and the rail line's patronage and operational model in this low residential and commercial density environment. The "low generalized interchange cost" station configuration will be described in detail later in the paper and show how all the time and financial cost components of the bus to rail interchange have been minimized.

\section{Perth Southern Rail Operational Model}

The transfer based operational model for the Southern Rail Line is based on a high level of convenience and a low generalized cost to passengers. The Western Australian Public Transport Authority (PTA) achieved this by providing an integrated multi-modal public transport service able to compete with the car for journeys from Perth's CBD to the key centers and southern suburbs.

The PTA maintains Strategic, Tactical and Operational (STO) control over Perth's public transport network, with bus operator contracts managed by the PTA, with the PTA retaining the service fare box revenue. The STO framework [5] defines the three levels, or tiers of activeties of the transport agency (see Figure 3).

The retention of Strategic and Tactical control over the network has enabled the PTA to deliver Perth's transfer oriented public transport system for the southern suburbs and through the introduction of specific operational attributes primarily:

- Integrated network design and timetabling;

- Integrated ticketing;

- A zone based fare system that enables seamless bus interchange;

- Additional elements such as the free Central Area Transfer buses.

\subsection{Integrated Ticketing and Fares}

The introduction of integrated multi-modal electronic ticketing prior to the opening of the Southern Rail Line enables convenient transferring between modes without the need to purchase separate tickets. In addition, the fare system used means there is no financial penalty for changing between modes, regardless of modal operator (all of whom are under tactical control of the PTA). The ticketing model for Perth is presented in Figure 5.

\subsection{Zone Based Fare Structure Facilitating Bus Interchange}

Perth's public transport broad zone based structure (shown in Figure 5) has enabled most, if not all, of the bus based feeder services to be "intra-zonal" trips.

Whereby the bus based trip to one of the Southern (or Northern) Rail line stations for a multi-zonal journey does not incur an additional financial cost for the journey. The zone based fare structure therefore enables the feeder bus services to travel along the urban highways that cross the Southern Rail Line stations to quickly interchange people at no financial cost to the passenger thus removing the financial cost penalty to intermodal transfers for the line.

The feeder buses are integrated into stations by placing these at the points where highway overpasses occur thus leading to a direct pedestrian feed-in down an escalator from the bus stop to the train. The feeder buses are integrated into stations by placing these at the points where highway overpasses occur thus leading to a direct pedestrian feed-in down an escalator from the bus stop to the train.

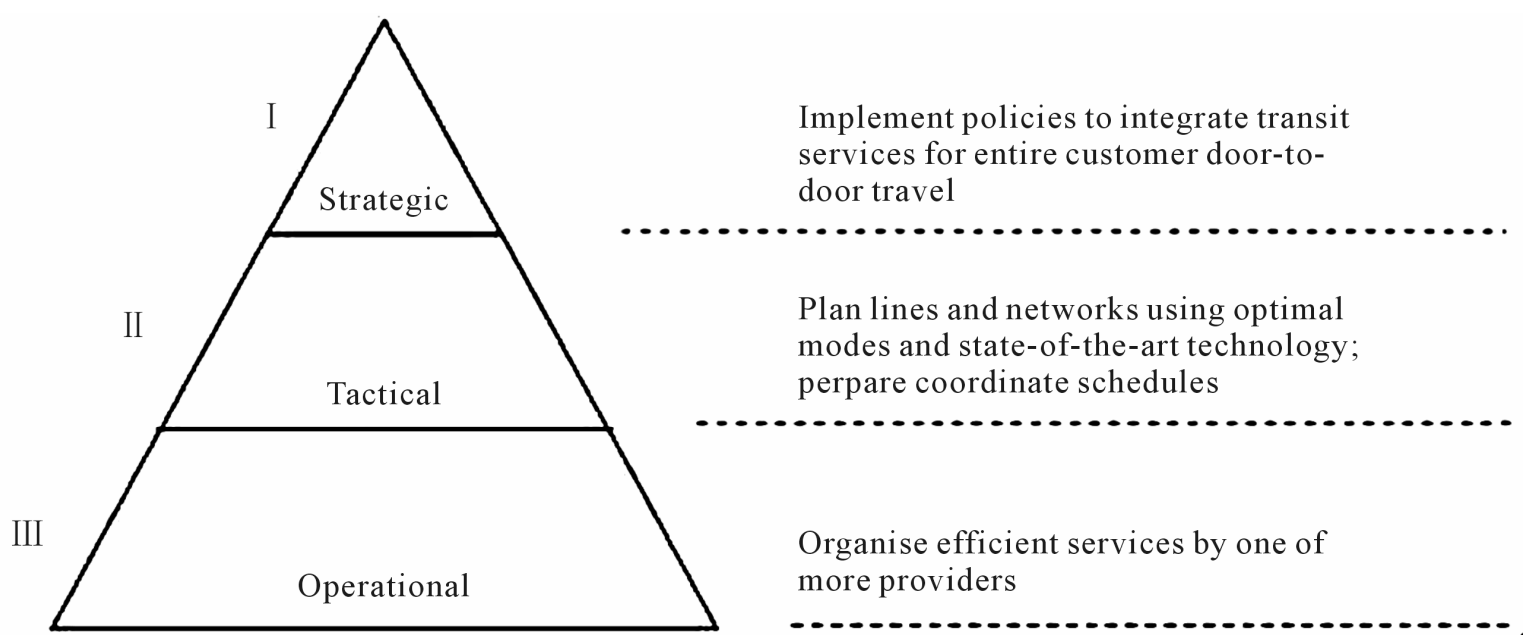

Figure 3. Conceptual transit operation framework [5]. 


\subsection{Regional Bus Network Structured to Feed the Southern Rail Line}

The Southern Rail Line's broad feeder bus patronage catchment is served by a comprehensive bus network that has been structured to enter the low density suburbs and quickly bring the bus patrons to the Southern Rail stations, as well as stations on other lines, to transfer to the rail network.

These transfers are not "forced" as the buses continue onto other key trip attractors and centres. However the system provides bus passengers the opportunity to transfer to a fast trip to the CBD (and other centres across the public transport network) at generally no additional financial cost as the majority of these bus trips are contained within a single travel zone (illustrated in Figures 4 and 5).

\subsection{Central Area Transfer Bus Services}

The Perth “Central Area Transfer" bus (CAT bus) services operate free of charge from the rail stations at Fremantle and Joondalup and within the Perth City Council municipal boundaries as a "Free Transit Zone", thus minimizing the cost of travel at either end of the trip origin and destination at these major centers.

To fund the CAT services, the Perth Parking Management Act, 1999 operates within the Perth CBD, and hypothecates the revenue generated to alternative non car based modes, and in particular public transport (it wholly funds the capital and operating costs of the Perth CAT bus services). This not only acts as a public transport revenue source (and PT trip cost reduction due to the CAT services), but as an additional cost (and disincentive) to private vehicle trips to the CBD.

\subsection{Perth Southern Rail Station Configurations}

As previously mentioned the Perth Southern Suburbs Rail Line corridor is located in the median of the Kwinana freeway for the majority of its distance, and as such the rail stations and their intermodal interchanges are located in the middle of the freeway as well. This constrained location reduces the opportunities for pedestrian catchments for the station. However it does have a number of advantages, in that the station does not require additional land, while the negative externalities of the rail operation are confined to an existing transport corridor.

The integration of a significant bus interchange at the entrance to each of the stations minimizes the transfer time cost between modes (as part of the low generalized cost trip model), and given its controlled nature makes a very safe environment to transfer between modes, and for accessing the park and ride facilities both during the day and at night. The challenges associated with its location are that it limits the amount of ancillary infrastructure that can be co-located within proximity of the station

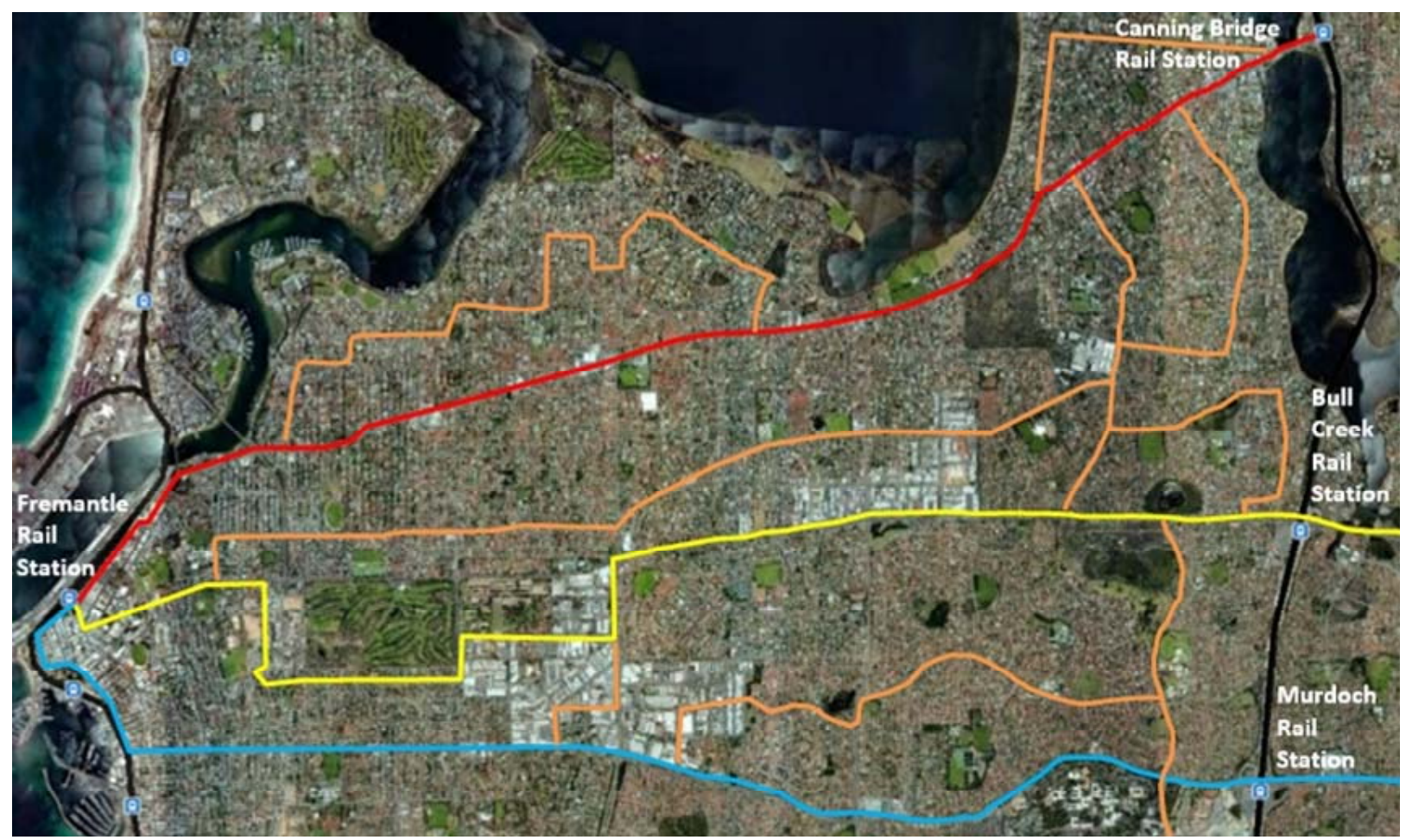

Figure 4. A sample of the western feeder bus catchments for the Southern Rail Line stations of Canning Bridge, Bull Creek and Murdoch [6]. 
Transperth fares effective Sunday 1 July 2012

\begin{tabular}{|c|c|c|c|c|c|c|}
\hline \multirow[b]{4}{*}{2 Sections } & \multicolumn{3}{|c|}{ STANDARD } & \multicolumn{3}{|c|}{ CONCESSION } \\
\hline & \multirow[t]{2}{*}{ Cash } & \multicolumn{2}{|c|}{ SmartRider - cost per journey } & \multirow[t]{2}{*}{ Cash } & \multicolumn{2}{|c|}{ SmartRider - cost per journey } \\
\hline & & $15 \%$ discount & $25 \%$ discount & & $15 \%$ discount & $25 \%$ discount \\
\hline & $\$ 1.90$ & $\$ 1.62$ & $\$ 1.43$ & $\$ 0.80$ & $\$ 0.68$ & $\$ 0.60$ \\
\hline 1Zone & $\$ 2.70$ & $\$ 2.30$ & $\$ 2.03$ & $\$ 1.10$ & $\$ 0.94$ & $\$ 0.83$ \\
\hline 2 Zones & $\$ 4.00$ & $\$ 3.40$ & $\$ 3.00$ & $\$ 1.60$ & $\$ 1.36$ & $\$ 1.20$ \\
\hline 3 Zones & $\$ 4.90$ & $\$ 4.17$ & $\$ 3.68$ & $\$ 2.00$ & $\$ 1.70$ & $\$ 1.50$ \\
\hline 4 Zones & $\$ 5.80$ & $\$ 4.93$ & $\$ 4.35$ & $\$ 2.30$ & $\$ 1.96$ & $\$ 1.73$ \\
\hline 5 Zones & $\$ 7.10$ & $\$ 6.04$ & $\$ 5.33$ & $\$ 2.80$ & $\$ 2.38$ & $\$ 2.10$ \\
\hline 6 Zones & $\$ 8.10$ & $\$ 6.89$ & $\$ 6.08$ & $\$ 3.20$ & $\$ 2.72$ & $\$ 2.40$ \\
\hline 7 Zones & $\$ 9.40$ & $\$ 7.99$ & $\$ 7.05$ & $\$ 3.80$ & $\$ 3.23$ & $\$ 2.85$ \\
\hline 8 Zones & $\$ 10.20$ & $\$ 8.67$ & $\$ 7.65$ & $\$ 4.10$ & $\$ 3.49$ & $\$ 3.08$ \\
\hline 9 Zones & $\$ 11.00$ & $\$ 9.35$ & $\$ 8.25$ & $\$ 4.40$ & $\$ 3.74$ & $\$ 3.30$ \\
\hline DayRider & $\$ 11.00$ & & & $\$ 4.40$ & $\$ 3.30$ & $\$ 3.30$ \\
\hline FamilyRider & $\$ 11.00$ & & & & & \\
\hline Student & & & & & 50 cents - & o discount \\
\hline
\end{tabular}

\section{Transperth Zone Map}

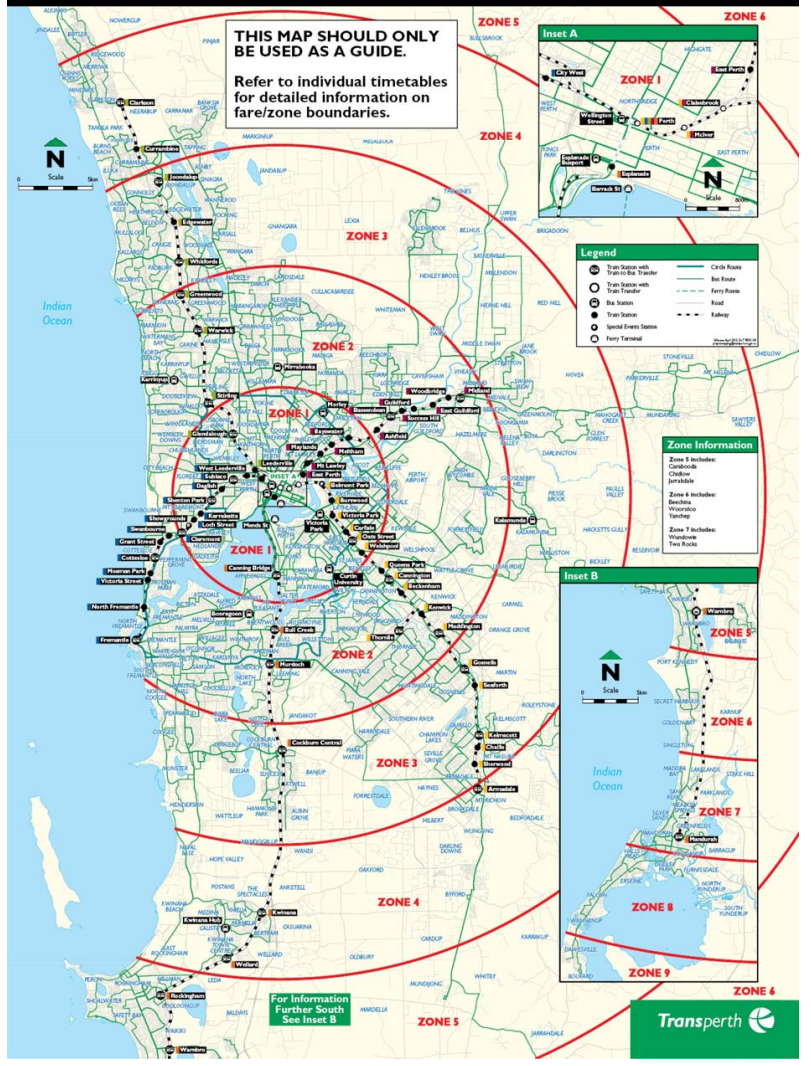

Figure 5. (Top) Transperth public transport fare structure [7]; (Bottom) transperth public transport zone map with the inner radius of $8 \mathrm{~km}$ subsequent rings $10 \mathrm{~km}$ [7].

(park and ride facilities, bike parking) and makes difficult any joint development of the stations with the private sector to implement Transit Oriented Development (TOD); several stations are now doing this by building high rise as a sound wall for other development on the other side. To provide an example of the physical loca- tion and operational attributes of one of the Perth Southern Suburbs rail line stations, the Murdoch Station at the South Street intersection has been selected.

\subsection{Murdoch Station}

Murdoch Station (shown in Figure 6) is now the busiest station of the entire Perth rail network (outside of Perth Central). This is an increasing trend as in 2010 Murdoch Station had 6733 boardings per day, and is now up to 8383 passenger boardings in March, 2012 with 4950 (59\%) of these being bus to train transfers, with approximately 700 park and ride spaces (8.3\%) [9].

In the absence of any data for the remaining patronage that is unaccounted for (2733 daily boardings), it is expected that these are made up of Kiss and Ride, Cycle and Ride and pedestrian access modes. The station has effectively no residential pedestrian catchment given the walking distance from property to the station is over $800 \mathrm{~m}$. This is due to the configuration of the road network adjacent to the station, and the lack of any pedestrian walkways (this is illustrated on Figure 7). The station is however within walking distance to a new and existing hospital precinct (approximately $700 \mathrm{~m}-800 \mathrm{~m}$ ) and is close to Murdoch University (approximately 1500 $\mathrm{m}$ ), though designs for redevelopment of a TOD over the car park have been drawn up by the State Government.

The key attribute of the Southern Rail Line stations, and Murdoch station in particular, is the extensive feeder bus services that travel at relatively high speeds along the crossing urban highways (such as South Street at Murdoch Station), these attract patronage to the rail line due to its speed, as it is generally at no additional cost as the feeder services are "intra zonal" trips.

\section{Perth Southern Rail Operational Modal Choice Model}

The generalized cost (GC) to the user of either public or private transport trip is characterized as a function of a time component, a monetary component, and opportunity component, which can be expressed as [11,12];

$$
\mathrm{GC}=\mathrm{TTC}+\mathrm{FC}+\mathrm{OC}
$$

- Travel Time Cost (TTC) is a function of the monetized value of the time spent (which includes waiting time, access time, travel time and where relevant transfer time) that has been calculated based on the trip purpose (journey to work) and the travelers income;

- Financial Cost (FC) is costs of fuel, wear and tear and any parking charge or toll on a car journey, or a public transport fare cost;

- Opportunity Cost (OC) is a function of the additional journey time the traveler experiences due to ei- 

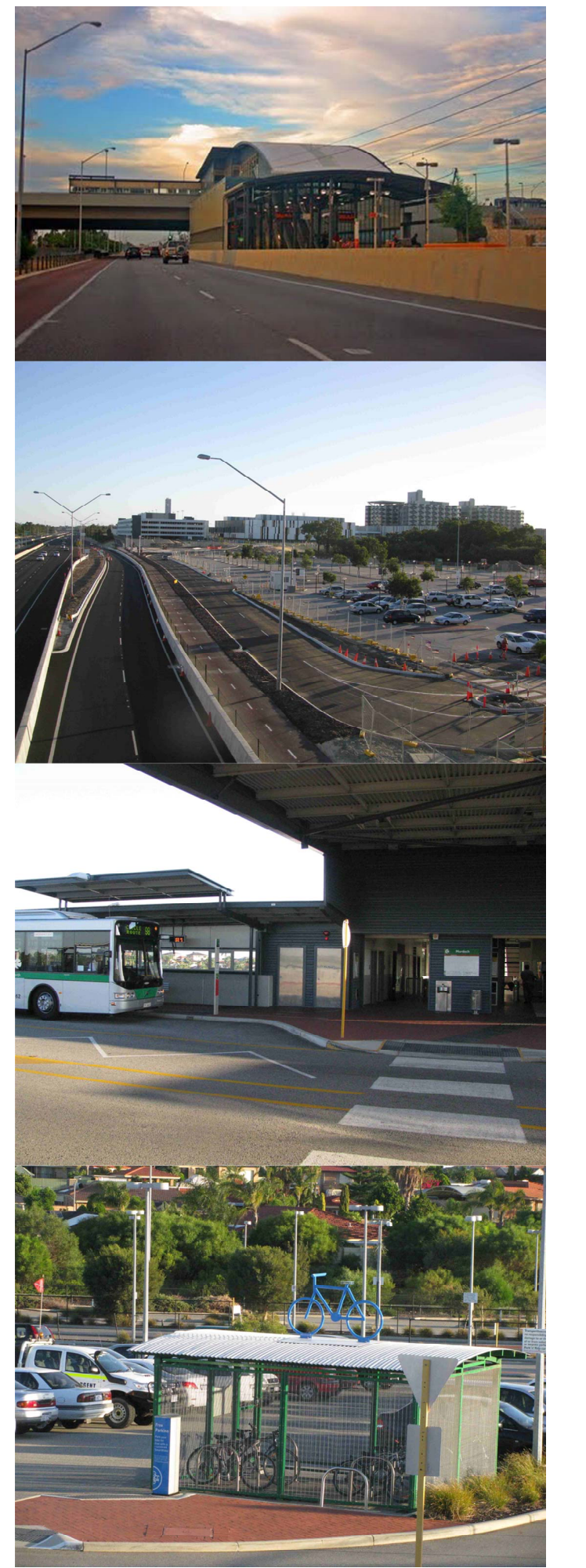

Figure 6. (Top) Murdoch station viewed from the kwinana freeway [8]; (Second top) park \& ride facilities in front of the new fiona stanley hospital and cycle way between the off ramp and park \& ride; (third Top) bus discharge and entry into the station, with electronic bus timetable information at bus bays; (Bottom) lockable bike parking for the cycle commuter, thus providing a full multimodal interchange.

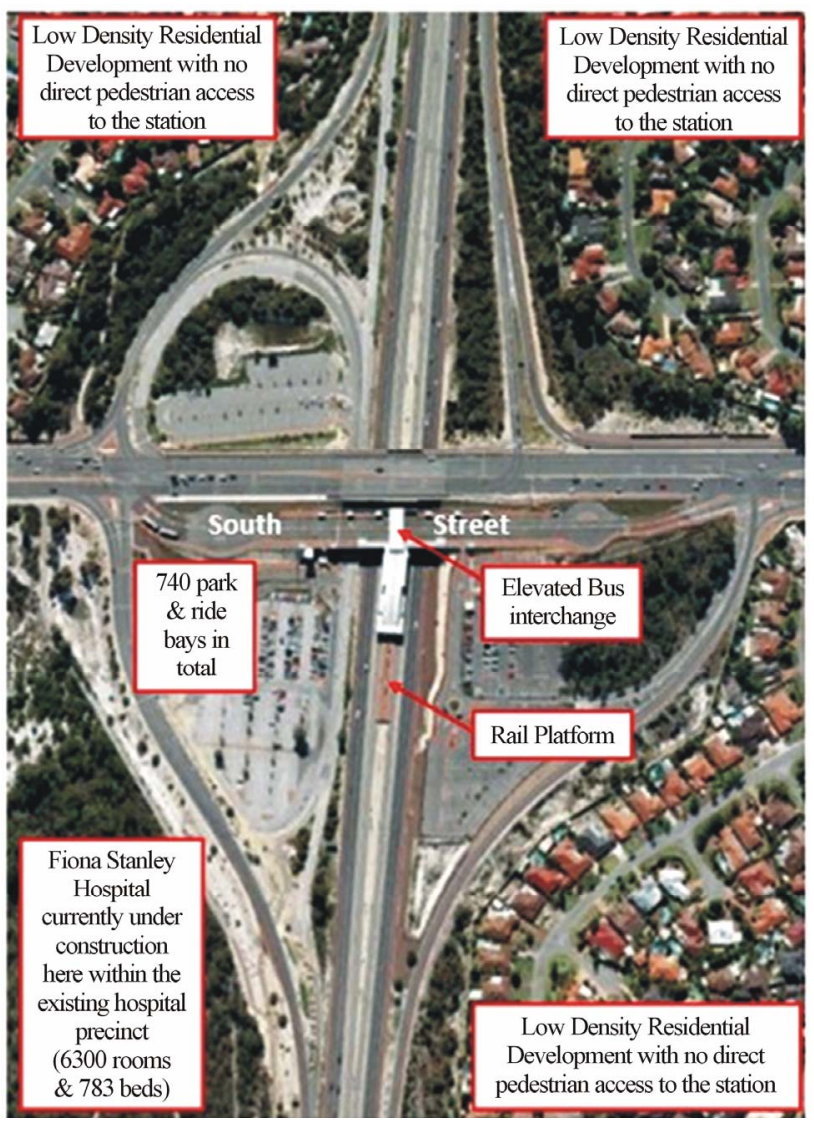

Figure 7. Murdoch station [10].

ther road based or public transport congestion, that could be spent doing something more productive.

The concept of generalized cost of a public or private trip is integral in transport planning for the development a transport link's modal choice model through the preparation of a modal utility (a quantitative measure of the benefit/dis-benefit of a particular transport mode). The Southern Rail modal choices can be viewed in a Nested Multinomial Logit model (Figure 8).

The modal utilities assigned to each mode are used to determine the probabilities of which mode would be used for a trip for the Southern Rail catchment to the CBD. Due to data limitations this paper has provided a quailtative presentation of the generalized cost input time cost, financial cost and opportunity costs components to understand the generalized cost for private vehicles and the Perth Southern rail line. The actual patronage figures presented later, validate the operational model proposed.

Whilst the financial cost of the car trip is increasing significantly due to the increases in cost of fuel and parking costs into the CBD (see Figure 9), it is the competitiveness of the Southern Rail Line with the private vehicle due to congestion on the competing Kwinana Freeway which gives the Southern Rail its real edge.

The effect of road based congestion on Perth's com- 


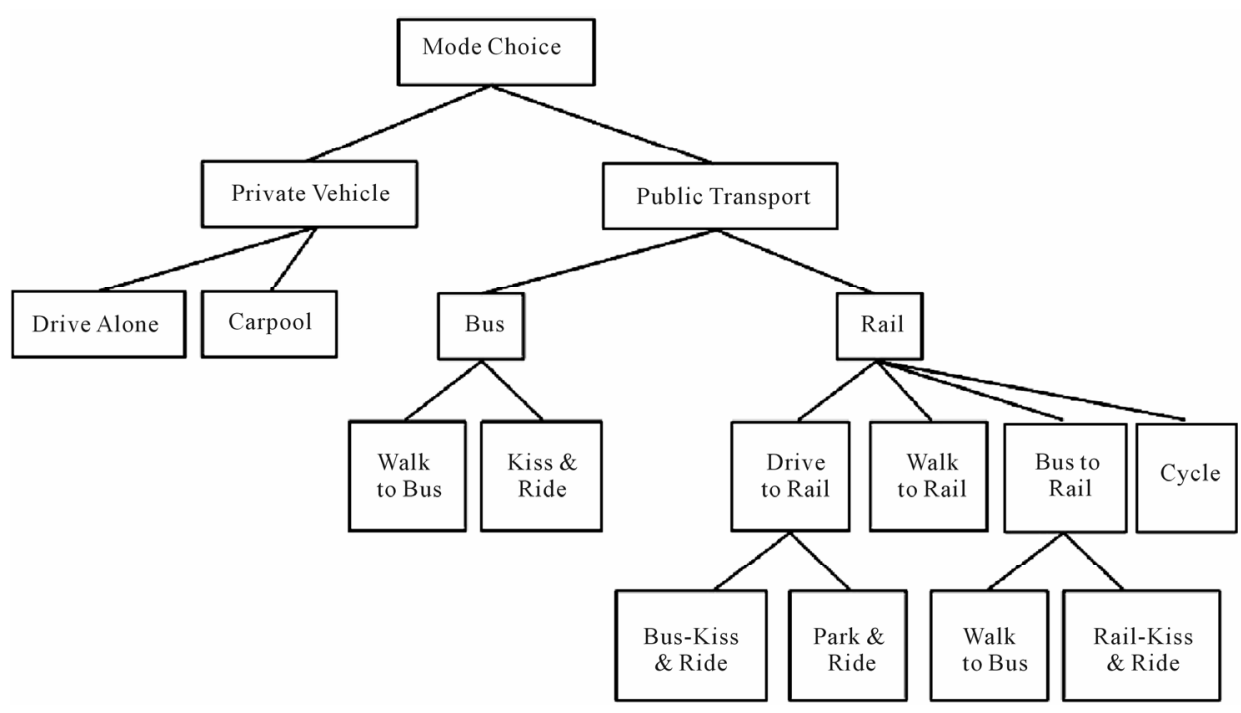

Figure 8. The Perth Southern Rail Line catchment multinomial nested logit mode choice model (using [13]).

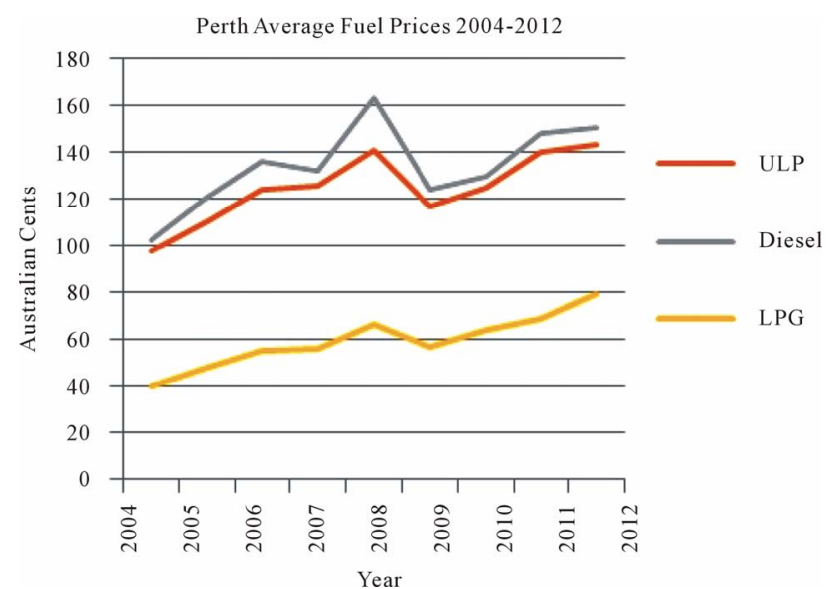

Figure 9. Perth retail fuel prices 2004-2012 [14].

muters has been verified by the Royal Automobile Club of Western Australia (RACWA), which in 2012 conducted their annual survey of 400 Perth businesses on the effects of road based congestion. This survey showed clearly that congestion was having a significant impact on the operation of their businesses and staff. This is reflected in Figure 10, which disturbingly shows that 82\% of business believed congestion was causing lost productivity and $74 \%$ believed it was reducing staff punctuality.

This road based congestion on Perth's road network is at its peak on the northern Mitchell freeway and southern Kwinana freeway, both of which are served by the high speed rail network, and it is argued that it is this road based congestion and high speed nature of the competing rail journeys that is driving the modal shift over the public transport in the Northern and in particular Southern catchments.

Table 1 qualitatively presents the generalized costs for a private vehicle and public transport "Journey to Work"

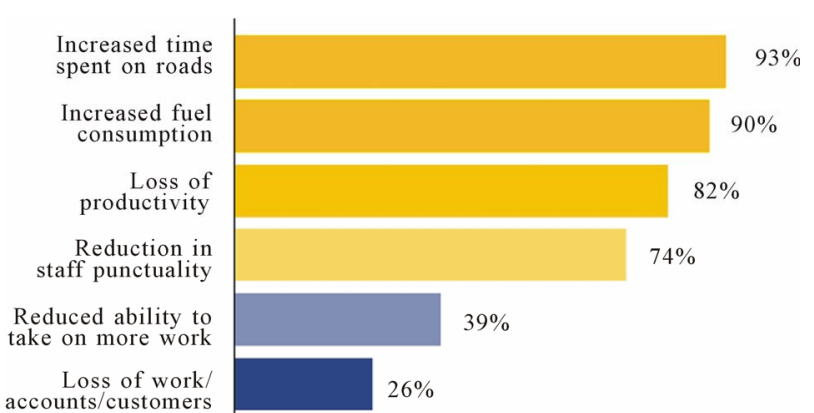

Figure 10. RACWA 2012 survey results on the prompted impact of traffic congestion [15].

trip to the CBD during the AM peak, and these are used to frame the mode choice discussion with regard to the Southern Rail catchment.

Table 1 clearly demonstrates that the public transport trip can provide a lower generalized cost for the trips to the CBD, and although this is only qualitative, the impact on passenger's modal utility and subsequent mode choice is obvious. This is reflected in the growth in the patronage of the Southern Rail line.

\section{Perth Southern Suburbs Rail Operational Performance}

The overall Perth rail network has increased patronage by 83\% from 2007 to 2012, (sees Figure 11). The transport business case for the Perth Southern Suburbs rail line was developed for the WA State government, by the consulting firm Sinclair Knight Merz (SKM) initially in 1999, and then this model was independently reviewed by Planning and Transport Research Centre in WA (PATREC) in 2004 [2].

Neither SKM nor PATREC were able to model how successful the Southern Rail Line would be at attracting 
patronage from the low density southern suburbs of Perth (as shown in Figure 2), as SKM's 2031 patronage forecast for the project was exceeded in the Southern Rail's first year of operation. The significantly more optimistic patronage model prepared by PATREC [2] (shown as PATREC Rail in Figure 11) still underestimates the impact of the patronage from the Southern Rail line, where the estimated 2021 total annual boardings for the network were exceeded in 2012.

Indeed the 2031 patronage forecast for the line and the greater Perth rail network is likely to be exceeded in 2014/2015 assuming that rail line does not get affected by a capacity constraint incurred by insufficient rolling stock provision which subsequently limits the growth of the network (Figure 11).

\section{Lessons of Fast Rail for Low Density Cities}

One of the most contentious debates in public transport planning is the role of transfer costs in deterring patronage due to time losses. This has been used to stop many rail projects $[18,19]$. The Southern Rail was designed to minimize transfer penalties by well-integrated bus interchanges and bus services. As a result these are responsible for $85 \%$ of the patronage, a figure much higher than for most rail systems. This seems to be acceptable to the patrons as the speed of the train means that the overall

Table 1. Qualitative generalised cost inputs for the perth southern rail mode choice model.

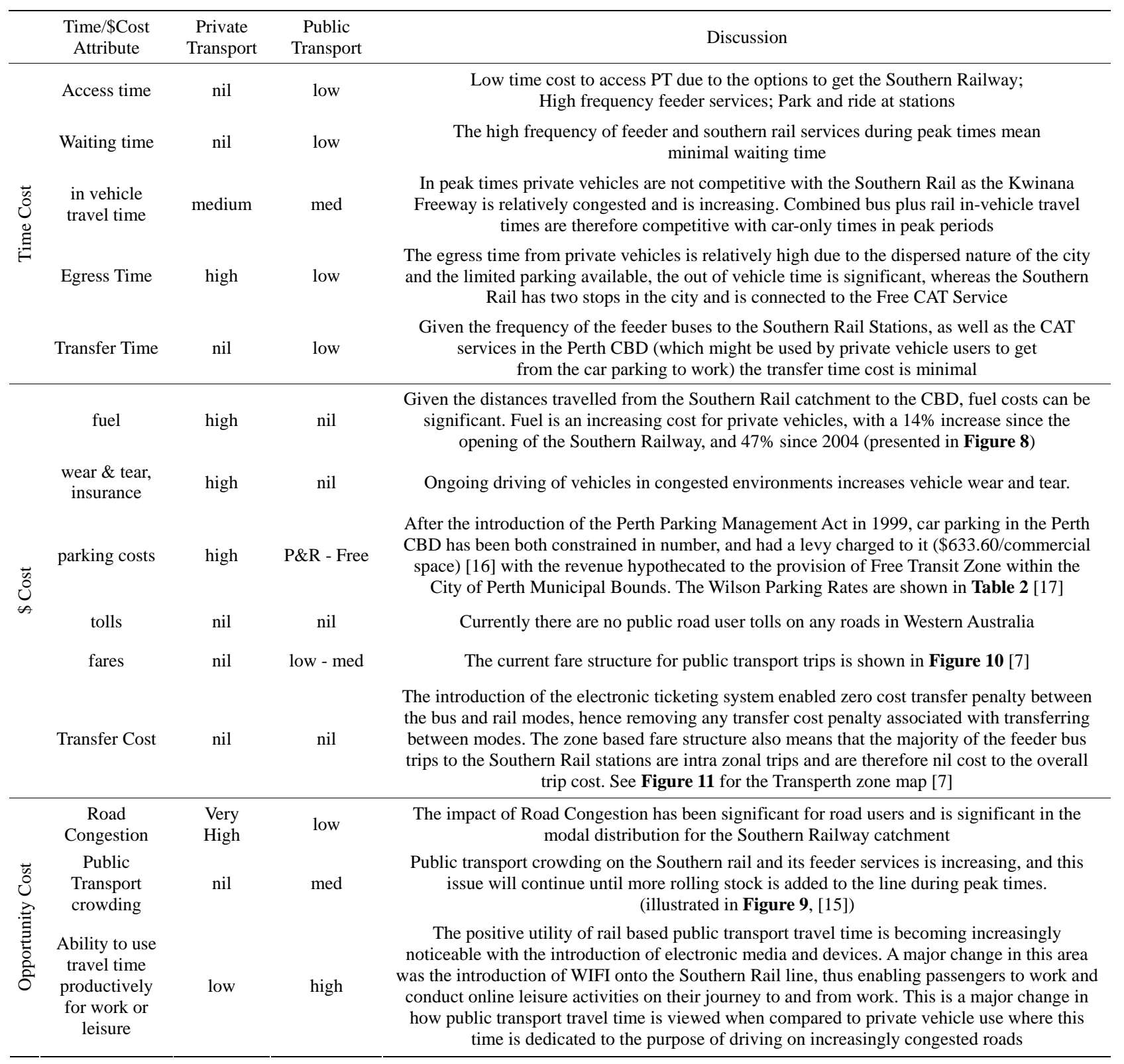


Annual Perth Rail Network Passenger Boardings
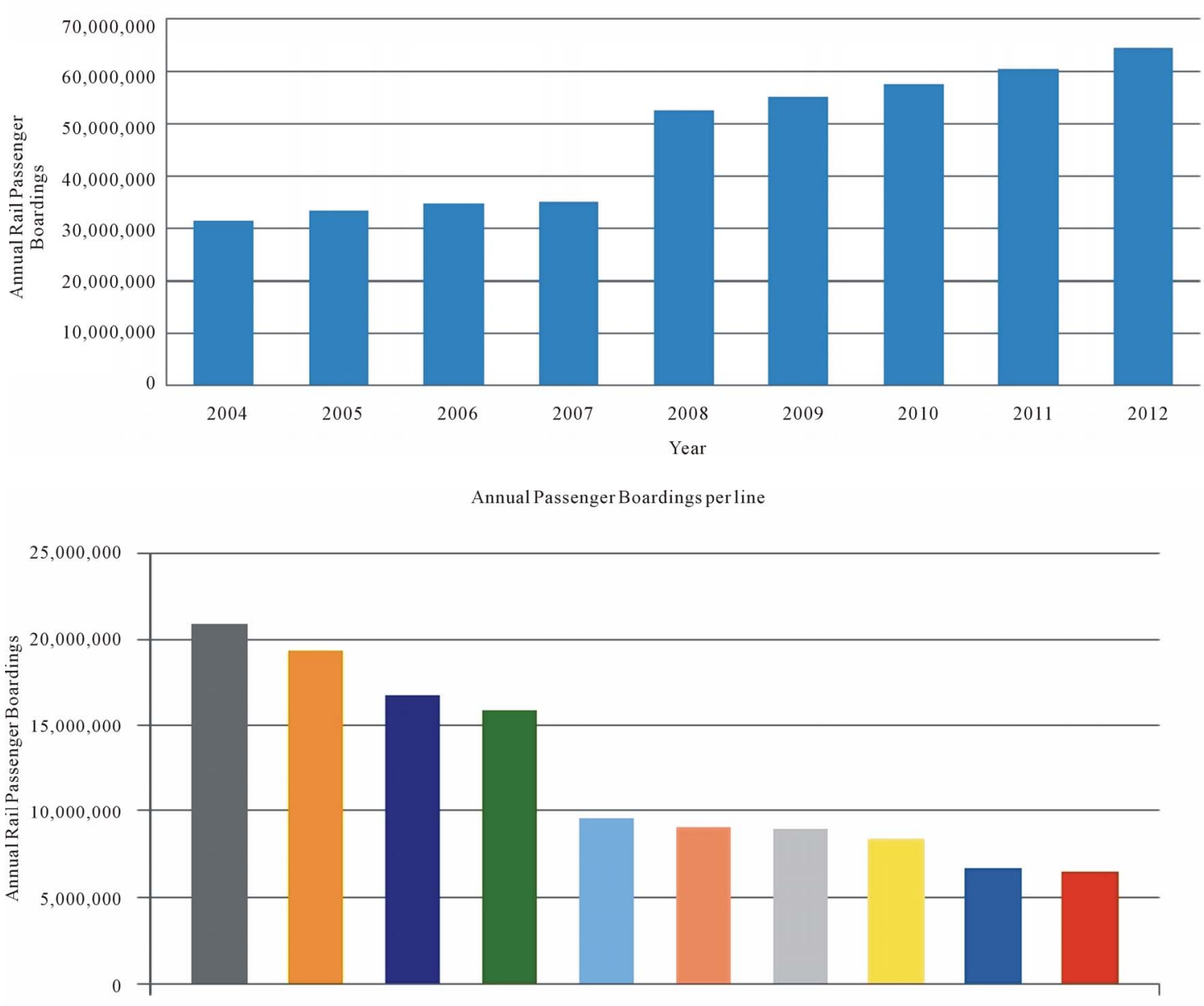

Mandurah 2012

Perth Rail Lines

Feasilibility Modelling, Actual \& Forecasting Rail Network Patronage for Metropolitan Perth

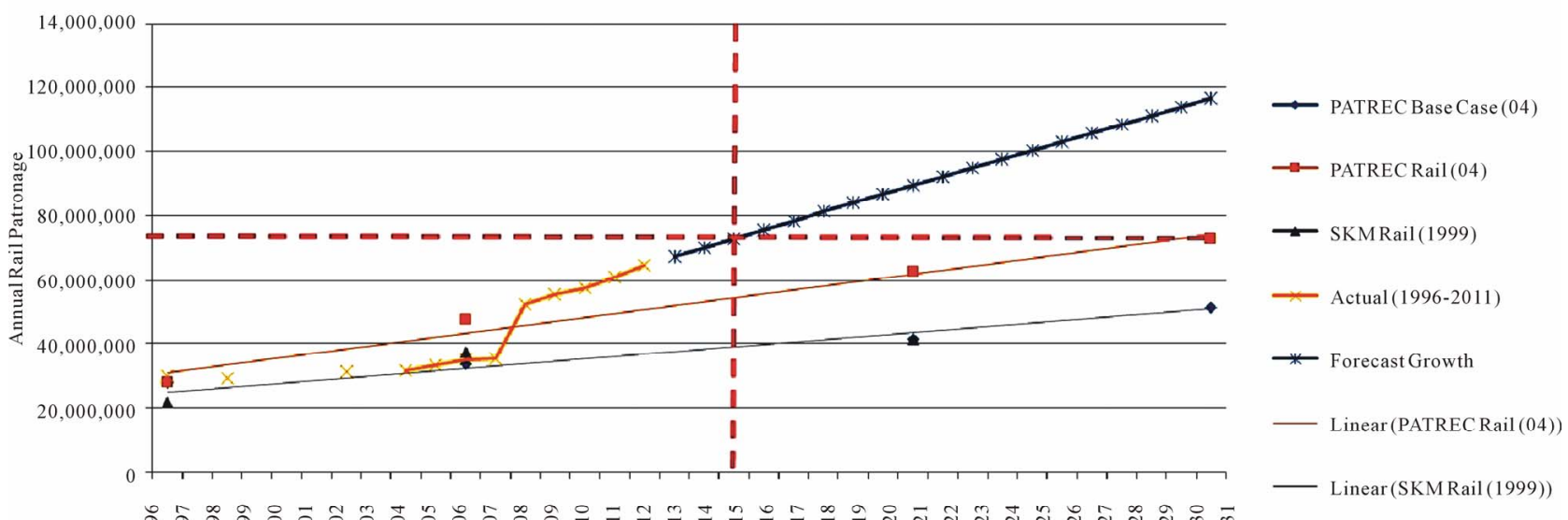

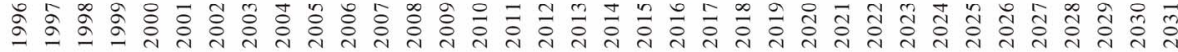

Figure 11. (Top) The Perth rail network lines annual patronage from 2004-2012 [4]; (Middle) Annual Perth rail network passenger boardings by line 2011-2012 [9]; (Bottom) Perth rail network annual patronage forecasts for the business case for the Southern Suburbs rail line [2,9], and the actual network patronage since the commencement of operation (purple line) with a propagation of the existing patronage into the future to be used to predict infrastructure capacity limitations (blue line). The red dashed cross over the graph illustrates that the rail network system 2031 patronage as specified [2] though this network patronage will be achieved in 2015 if current patronage growth continues (subject to capacity constraints). 
journey saves time compared to the private vehicle.

There would appear to be a lesson here for all rail planning but especially high speed rail: it is essential to minimize transfer penalties and create speeds that mean the generalized costs of choosing to travel on fast rail are lower than the alternatives (car, bus or plane).

The Perth Southern Rail Line has maintained a strong focus on the competitiveness of the public transport against the private motor vehicle in a time and financial generalized cost model for access from the southern suburbs to the Perth CBD and the rest of the rail network. This is illustrated by:

- The competitiveness of the train to the car in time due to the high speed of the trains (maximum speed 137 $\mathrm{km} / \mathrm{hr}$ ) compared to the car (freeway speed limit 100 $\mathrm{km} / \mathrm{hr}$ ).

- The congested nature of the competing Kwinana Freeway, which is increasing with peak hour travel speeds being much lower than the theoretical speed limit.

The frequency of the feeder bus services and the ease and speed of interchange between the bus and rail modes, minimizing the time penalty for transferringbetween modes

- The introduction of the electronic ticketing system that enabled zero cost transfer between the bus and rail modes, hence removing any transfer cost penalty associated with transferring between modes.

- The majority of the feeder bus services that transfer to the rail stations do very quickly and conveniently, and operate within the single transport ticketing zones, therefore not adding to the trip cost for the overall journey.

This model for the minimization of public transport generalized cost when compared to the private vehicle has enabled Perth Southern Suburbs rail line to be very competitive with the private vehicle in a region where the Southern Rail Line is located. This area is where the private vehicle has been historically extremely dominant due to low dwelling and population density, and long travel distances for the journey to work.

The low generalized cost network design minimizes the time and financial cost for the multimodal trip and induces traditionally car based ridership onto the transfer designed feeder services to the stations, and this is the key success for the intermodal public transport model that operates for the Southern Rail Line.

The application of the Southern Rail model to the design of high speed intra-city and regional rail for large, low density cities as well as very fast intercity train systems would appear to be clear.

\section{Acknowledgements}

The authors would like to thank members of the Western
Australian Department of Transport and Western Australian Public Transport Authority for their support in providing data for this research.

\section{REFERENCES}

[1] R. Waldock, P. Martinovich, A. Cartledge and R. Hamilton, "New Metro Rail Project-Lessons Learned May 2008,” Public Transport Authority, Perth, 2003. http://www.ceiid.wa.gov.au/Docs/KNF_200805/MAY08NewMetroRailProject.pdf

[2] PATREC, Perth's South West Metropolitan RailwayBalancing Benefits and Costs Report for the Public Transport Authority of Western Australia by the Planning and Transport Research Centre, 2004.

[3] Western Australian Department of Planning, Directions 2031 and Beyond, Metropolitan Planning and Beyond the Horizon, 2013.

http://www.planning.wa.gov.au/dop_pub_pdf/plan_direct ions2031_part1.pdf

[4] Western Australia Department of Transport, "Transperth Train Network," Train Boardings by Station on an Average March Weekday, 2011.

[5] Vuchic, "Urban Transit-Operations, Planning and Economics,” John Wiley \& Sons, Inc., Hoboken, 2005, pp. 456-457.

[6] Google Earth Image, 2013.

[7] Transperth, 2011. http://www.transperth.wa.gov.au/TicketsandFares.aspx

[8] Wikipedia, Murdock Railway Station Photos, 2013. http://en.wikipedia.org/wiki/Murdoch_railway_station

[9] Western Australia Department of Transport, "Daily Rail Patronage Data from the Perth Rail network,” 2012.

[10] Google Earth, Image Downloaded from Google Earth, 2012.

[11] Australian Transport Council, "National Guidelines for Transport System Management in Australia, Volume 3Appraisal of initiatives,” 2006.

http://www.atcouncil.gov.au/documents/files/National_G uidelines_Volume_3.pdf

[12] Y. Crozet, “Time and Passenger Transport' Round Table 127: Time and Transport," 2005. http://halshs.archives-ouvertes.fr/docs/00/19/45/83/PDF/ ECMT_CROZET.pdf

[13] C. Papacostas and P. Prevedouros, "Mode Choice,” Transportation Engineering \& Planning, pp. 391-399.

[14] Western Australia Department of Commerce and Finance, "Perth Fuel Prices," 2012.

http://www.commerce.wa.gov.au/Corporate/Media/statem ents/2012/December/Perth_fuel_prices_highest_in_2012. html

[15] RACWA, "RACWA Business Wise Congestion Survey,” 2012.

http://rac.com.au/Motoring/Roadside-Assistance/For-your -business/ /media/Businesswise/Businesswise_congestio n_survey2012_V2.ashx

[16] Western Australia Department of Transport, "Perth Park- 
ing Management Act, 1999,” 2013.

http://www.transport.wa.gov.au/mediaFiles/DOT_R_Park Pol.pdf

[17] Wilson Parking, "Parking Rates for the Queens Complex in the Perth CBD," 2013. http://www.wilsonparking.com.au/go/wilson-car-parks/w a/queens-complex

[18] D. Hensher, “A Bus-Based Transit Way or Light Rail? Continuing the Saga of Choice versus Blind Commit- ment,” Road and Transport Research, Vol. 8, No. 3, 1999, pp. 3- 21.

[19] G. Currie, "Research Perspectives on the Merits of Light Rail versus Bus," Presentation from the BITRE Colloquium, 18-19 June 2009.

http://www.infrastructureaustralia.gov.au/publications/file s/LightRailVSBus.pdf 